\title{
Fracture of a pacemaker lead
}

\section{Shu-Hsuan Chang MD, Che-Kim Tan MD, Shih-Huang Lee MD}

Previously published at www.cmaj.ca
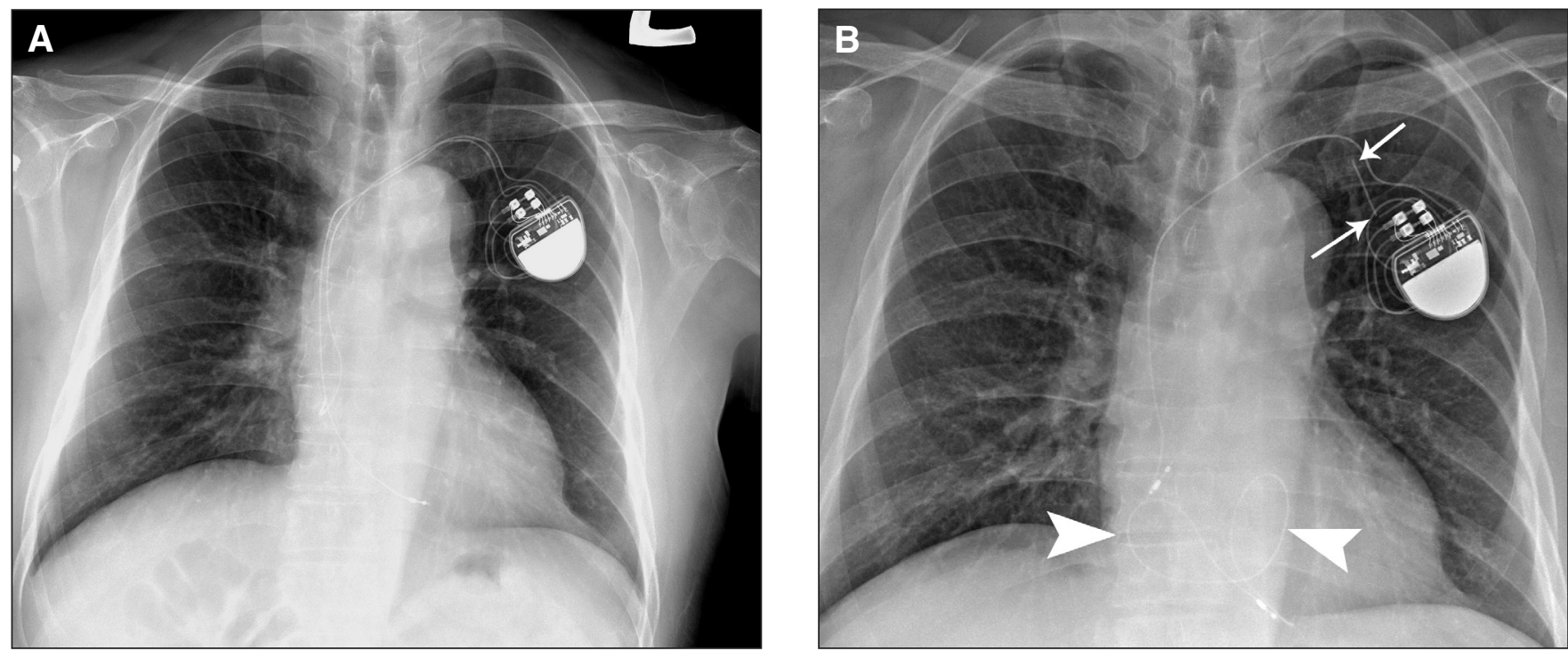

Figure 1: (A) Radiograph of the chest of a 68-year-old man after implant of a dual-chamber pacemaker. (B) A radiograph taken 2 years later shows fracture of the ventricular lead with 2 fracture points (arrows) in the generator pocket and at the entry site of the left subclavian vein. The distal segment of the broken lead has migrated to the right ventricle, where the lead loops (arrowheads) in the right atrium and ventricle.

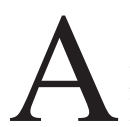
68-year-old man had intermittent dizziness after participating in a Judo competition. The patient had a dual-chamber pacemaker that had been implanted 2 years earlier for a high-grade atrioventricular block (Figure 1A).

On assessment, an electrocardiogram showed evidence of a high-grade atrioventricular block with a ventricular rate of 45 beats/min and an intrinsic atrial rhythm of 90 beats/min. A radiograph of the chest showed that the ventricular lead of the pacemaker was fractured into 3 parts (Figure 1B) but the atrial lead was intact. The broken lead was extracted and a new pacemaker was implanted; the patient was discharged uneventfully.

The incidence of lead fractures in pacemakers is about $1 \%-4 \% .^{1,2}$ Most fractures occur in the area just lateral to the subclavian venous entry site $^{1,2}$ as a result of compression of the lead between the clavicle and the first rib or entrapment of

From the Division of Cardiology (Chang, Lee), Shin Kong Wu Ho-Su Memorial Hospital, Taipei; the Department of Intensive Care Medicine, Chi-Mei Medical Centre (Tan), Tainan; and the Department of Medicine, Fu Jen Catholic University (Lee), Taipei Hsien, Taiwan

Cite as CMAJ 2009.DOI:10.1503/cmaj.082092 the lead by soft tissue in the costoclavicular space. Fractures in pacemaker leads during weightlifting have been reported. ${ }^{3}$ In our patient, the cause was likely excessive movement of the upper limbs and direct trauma. Patients with implanted pacemakers should be reminded to avoid rigorous exercise of the upper limbs and direct compression of the chest wall. Our patient was fortunate not to be completely dependent on the pacemaker. If he had been, the situation could have led to a very different outcome. To reduce the risk of lead fracture, he stopped his practise of Judo after discharge and took up running instead.

This article has been peer reviewed.

Competing interests: None declared.

\section{REFERENCES}

1. Alt E, Volker R, Blomer H. Lead fracture in pacemaker patients. Thorac Cardiovasc Surg 1987;35:101-4.

2. Magney JE, Flynn DM, Parsons JA, et al. Anatomical mechanisms explaining damage to pacemaker leads, defibrillator leads, and failure of central venous catheters adjacent to the sternoclavicular joint. Pacing Clin Electrophysiol 1993; 16:445-57.

3. Deering JA, Pederson DN. Pacemaker lead fracture associated with weightlifting: a report of two cases. Mil Med 1993;158:833-4. 